\section{What is the Clinical Importance of an Evanescent Rash in a Patient with Fever of Unknown Origin?}

Fever of unknown origin (FUO) is a challenging problem for the practicing physician all over the world; requiring both knowledge and experience. Rheumatologic disorders are among the causes of FUO. The most common rheumatologic disorder causing FUO has been adult-onset Still's disease (ASD) (1).

ASD is the adult form of systemic-onset juvenile rheumatoid arthritis. It is mostly seen between the ages of 16 and 35 . The diagnosis has been based on the criteria of Cush et al (2) and requires the presence of the following: 1) high fever $\left.\left(\geq 39^{\circ} \mathrm{C}\right), 2\right)$ arthralgia or arthritis, 3) rheumatoid factor $\left.(-), 4\right)$ antinuclear antibody $(-), 5)$ leukocytosis $\left.\left(\geq 15,000 / \mathrm{mm}^{3}\right), 6\right)$ Still-rash 7) pleuritis or pericarditis and 8) hepatomegaly or splenomegaly or systemic lymphadenopathy. All of the first 4 criteria and two of the last 4 are needed for the diagnosis. The exclusion of other etiologies is essential to establish the diagnosis. The 'Still's rash' is salmon pink, macular or maculopapular.

This rash is present during the illness in nearly $90 \%$ of the cases (3). In an ASD series, an evanescent rash occurred with the fever spike and disappeared when the fever decreased in 79\% (46/62) (4). Ohta et al (5) conducted a multicenter survey of Japanese patients with ASD. In their study, skin involvement was seen in $97 \%(86 / 89)$. Among them, 72 out of 83 patients $(87 \%)$ had typical rash usually appearing during fever. During the last 22 years (between 1980 to 2001), we have diagnosed ASD in 17 out of 125 FUO patients (14\%). A skin rash has been observed during the illness in $13(76 \%)$ patients (maculopapular in 11, urticarial in 2). In 11 ASD patients, an evanescent rash occurred with fever spike and disappeared when it dropped. This finding has not been observed in other FUO patients. On the other hand, we have followed 110 patients who were admitted with fever and rash during the last 22 years. These patients did not fulfill the criteria of FUO. Also this type of fever and rash association was not observed in this group. In conclusion, in a patient with FUO, an evanescent maculopapular rash observed during the fever spike strongly suggests ASD.

\section{Ali Mert and Resat Ozaras}

Clinical Bacteriology and Infectious Diseases, Cerrahpasa Medical Faculty, University of Istanbul, Istanbul, Turkey

Reprint requests should be addressed to Dr. Ali Mert, Cerrahpasa Medical Faculty, Department of Clinical Bacteriology and Infectious Disease, University of Istanbul, 34303 Aksaray, Istanbul, Turkey

\section{References}

1) Hirschmann JV. Fever of unknown origin in adults. Clin Infect Dis 24: 291-300; quiz 301-302, 1997.

2) Cush JJ, Medsger TA, Christy WC, Herbert DC, Cooperstein LA. Adultonset Still's disease. Clinical course and outcome. Arthritis Rheum 30: 186-194, 1987.

3) Ohta A, Yamaguchi M, Kaneoka H, Nagayoshi T, Hiida M. Adult Still's disease: review of 228 cases from the literature. J Rheumatol 14: 11391146, 1987.

4) Pouchot J, Sampalis JS, Beaudet F, et al. Adult Still's disease: manifestations, disease course, and outcome in 62 patients. Medicine (Baltimore) 70: 118-136, 1991.

5) Ohta A, Yamaguchi M, Tsunematsu T, et al. Adult Still's disease: a multicenter survey of Japanese patients. J Rheumatol 17: 1058-1063, 1990. 